Case Report

\title{
Diphtheria: a re-emerging public health challenge
}

\author{
Mustapha Y. Abubakar, Jamila Lawal*, Hassan Dadi, Umaru S. Grema
}

Department of Otorhinolaryngology, National Ear Care Centre, Kaduna, Nigeria

Received: 03 September 2019

Revised: 13 November 2019

Accepted: 14 November 2019

\author{
*Correspondence: \\ Dr. Jamila Lawal, \\ E-mail: drjaylaw@gmail.com
}

Copyright: (C) the author(s), publisher and licensee Medip Academy. This is an open-access article distributed under the terms of the Creative Commons Attribution Non-Commercial License, which permits unrestricted non-commercial use, distribution, and reproduction in any medium, provided the original work is properly cited.

\begin{abstract}
Diphtheria is a highly contagious, potentially life threatening bacterial infection caused by Corynebacterium diphteriae. Diphtheria is transmitted from person to person, usually through respiratory droplets and can lead to severe breathing problems, heart failure, blood disorders and death. Diphtheria was basically eliminated after the introduction of the vaccine in the 1940-1950s. However there is presently global concern that diphtheria is reemerging. We herein report nine cases of diphtheria presenting within a period of six months. All cases presented with sore throat, fever, membrane in the oropharynx and bull neck. Eight of the cases had never been immunized against diphtheria. All cases progressed and developed various complications with 8 of the cases dying. None of the cases had diphtheria antitoxin. This cases present the potential for this highly fatal but preventable disease reemerging and the need to be aware of epidemiological features, clinical signs and symptoms of diphtheria so that cases can be promptly diagnosed and treated, and further public health measures can be taken to contain this serious disease.
\end{abstract}

Keywords: Diphtheria, Diphtheria antitoxin, Nigeria, Vaccination

\section{INTRODUCTION}

Corynebacterium diphtheriae is a non-spore-forming, non-encapsulated, non-motile, Gram-positive bacillus which produces an exotoxin. It commonly affects the nasal cavities, oropharynx and larynx causing necrosis of tissues and formation of pseudo membranes which lead to respiratory obstruction. Dissemination of the toxins in the blood can cause other complications such as septicemia, disseminated intravascular coagulopathy, myocarditis, heart failure, renal failure and death. Corynebacterium ulcerans causes cutaneous disease. Diphtheria is primarily a disease of childhood affecting children under the age of 12 years but also occurs in adults older than 40 years of age.

Pattern of epidemiology of diphtheria has changed over time due to the introduction of vaccination- Expanded Programme on Immunization and changes in socioeconomic conditions, with dramatic reduction in the incidence of diphtheria worldwide. South East Asia, particularly India has been the largest contributor to increasing incidence worldwide while incidences in Africa and Europe have been declining. ${ }^{1}$ However there has been no progress made in reducing the incidences over the last 10 years globally. ${ }^{2}$

Diphtheria incidence cases are under reported in Africa and Nigeria is not an exception. The number of reported cases of diphtheria in Nigeria have been declining with reported cases of 1768 in 1990, 3995 in 2000 and 1870 in 2018. ${ }^{3}$ There was however an eleven years period of missing diphtheria data from Nigeria in the WHO/UNICEF joint reporting process. During this period there were cases of diphtheria outbreak reported in the literature, this is as a result of the poor surveillance and reporting system available in the country. ${ }^{4,5}$

The World health organization recommends three doses primary series diphtheria vaccine in infancy while subsequent diphtheria vaccines depends on the epidemiologic pattern of disease in each country. ${ }^{6}$ Booster 
doses are recommended for developed countries which need to compensate for the loss of natural boosting from the environment. The Nigerian National Immunization Schedule advocates that all children be given the vaccine at 6th, 10th and 14th weeks of life with booster dosses after 10 years. For adults, it is recommended that one receives the tetravalent vaccine once, followed by tetanus-diphtheria vaccine every 10 years. Children, adolescents or adults who were unimmunized or incompletely immunized are offered accelerated vaccination. In the event of an outbreak, selective vaccination campaigns targeting at-risk groups has also been recommended. ${ }^{7,8}$

The mainstay of treatment of a suspected or confirmed diphtheria case is prompt administration of diphtheria antitoxin (DAT). Universally accessibility to DAT is limited, leading to delay or non-availability of equine DAT. The antitoxin does not neutralize toxin that is already bound to tissues, hence delaying its administration is associated with an increased mortality. ${ }^{9}$

\section{CASE REPORT}

Nine patients were referred to the National Ear Care Centre, Kaduna from Various primary health care centres in the state within a period of six months. They consisted of eight children age range 4-12 and an adult 42 years of age. There were eight females and one male. Only five of the cases presented within five days of onset of symptoms. All nine patients presented with symptoms of sore throat, odynophagia, bull neck, membrane in the throat and fever. In addition seven of the cases had airway obstruction and three had petechial rashes. All cases progressed and developed various complications: six had acute renal injury, four developed airway obstruction, epistaxis and disseminated intravascular coagulpopathy. Two had palatal paralysis, two developed shock and one had cardiac arrhythmia. Eight of the cases had never been immunized against diphtheria.

Diphteroid species was cultured from the throat swab of five of the cases while one cultured diphteroid and streptococcus, three of the swabs cultured no isolates. One of the swabs was sent for polymerase chain reaction and the Dtex gene was isolated. All nine cases had systemic antibiotics Four of the cases had emergency tracheostomy at presentation due to airway obstruction probably due to membrane in the larynx and four had blood transfusion. None had diphtheria anti toxin. Seven died due to complications.

\section{DISCUSSION}

The commonest presentations were sore throat, odynophagia, oropharyngeal membrane that leads to bleeding when peeled off, bull neck, and low grade fever. All cases had received some form of primary care at various health facilities (antibiotics and analgesics) before presentation. Reason for delay in presentation may not be unrelated with failure at quick recognition of the clinical syndrome of diphtheria by the initial attending health care personnel. A great percentage were referred when airway obstruction worsened or due to epistaxis. Four of the patients with severe airway obstruction probably due to pseudo-membrane covering the larynx had emergency tracheostomies. All the patients received antibiotics (penicillin, ceftriaxone, and erythromycin), analgesics, fluid and electrolyte therapy and steroid. However most had rapid progression of the disease and developed complications. Four cases developed disseminated intravascular coagulopathy and had blood transfusion. The commonest complication was acute renal injury $(66.7 \%)$ then airway obstruction, epistaxis and bleeding diathesis accounting for $44.4 \%$ each. Two cases had palatal paralysis and shock while 1 had cardiac arrhythmia. The case fatality rate was $77.8 \%$ of which three occurred within the first 24 hours of admission and the remaining four between 2-5 days on admission. The two survivors were of the older age groups (12 and 42 years) and had less severe symptom and complications (epistaxis, palatal paralysis and arrhythmia). This may be due to the older patients having a larger airway and better immune response.

All cases reported at primary health care facilities or rural medical outlets that had no expertise or facility to diagnose diphtheria and refer appropriately. Health care delivery is generally poor in Nigeria with factors such as poor management of human resources, inequitable and unsustainable health care financing, unpredictable economic and political relations, corruption and illiteracy affecting delivery of essential health services in the country. ${ }^{10}$

Eight of the cases $(88.8 \%)$ had no prior immunization against diphtheria and were of low socioeconomic status which is in keeping with established literature. ${ }^{9}$ Immunization rates in northern Nigeria are some of the lowest in the world with coverage in the north east being as low as $6 \%$. As a result, thousands of children are victims of vaccine-preventable diseases. There are various reasons for the low rates of immunization which include factors such as misconceptions about immunizations due to low confidence and lack of trust, religious influence, failure of the vaccines due to poor cold chain and shortage of vaccine and immunization supplies. ${ }^{11}$

None of the cases received DAT due to its unavailability. This in addition to late presentation may have contributed to the high case fatality rate recorded. Effective treatment of diphtheria cases require quick access to and administration of DAT. Presently, DAT is available from the Centre for Disease Control (CDC) under an Investigational New Drug protocol. In the developed world, physicians suspecting a case of diphtheria can contact the CDC for antitoxin. However, in Nigeria, in the event of a suspected or confirmed case of diphtheria, there is a bureaucratic ladder that involves reporting to 
the state epidemiologist who then informs the ministry of health who forwards request for the antitoxin to the CDC. The time taken to identify a manufacturer with remaining supply within expiry date (if at all available), and the time to arrange for shipment, may mean the supply arrives too late to save the lives of the patients. Regional stockpiles that can be readily accessed may be a preferable solution.

Six of the nine oropharyngeal swabs microscopy cultured diphtheroid species. One of these samples sent for PCR testing isolated the Dtex gene, confirming the diphtheria infection and a possible outbreak of the disease within Kaduna metropolis.

\section{CONCLUSION}

Poor immunization, low socioeconomic status, late presentation, inadequate health care delivery system and lack of DAT contributed to the high fatality of cases in this study. There is need to strengthen disease surveillance for this re-emerging and highly fatal preventable disease for proper control. As long as diphtheria is still epidemic, the need for strengthening of routine immunization and introduction of booster doses is required. Availability and easy accessibility of DAT cannot be over emphasized.

\section{ACKNOWLEDGEMENTS}

The authors would like to acknowledge the management of the National Ear Care Centre for the general support.

Funding: No funding sources

Conflict of interest: None declared

Ethical approval: Not required

\section{REFERENCES}

1. Delbridge L, Guinea AI, Reeves TS. Total thyroidectomy for benign multinodular goiter. Arch Surg. 1999; Besa NC, Coldiron ME, Bakri A, Raji A, Nsuami MJ, Rousseau C, et al. Diphtheria outbreak with high mortality in northeastern Nigeria. Epidemiol Infect. 2014;142:797-802.

2. Santos LS, Sant'anna LO, Ramos JN, Ladeira EM, Stavracakis-Peixoto R, Borges LL, et al. Diphtheria outbreak in Maranhao, Brazil: microbiological, clinical and epidemiological aspects. Epidemiol Infect. 2015;143:791-8.
3. Wagner KS, White JM, Lucenko I, Mercer D, Crowcroft NS, Neal S, et al. Diphtheria in the post epidemic period, Europe, 2000-2009. Emerg Infect Dis. 2012;18:217-25.

4. Sheena K, Pushpa K, Kalpana G, Jaichand J, Rejitha $\mathrm{K}$, Geetha R. Re-emergence of diphtheria in Malappuram district, North Kerala, India. 2018;20(1):37-9.

5. McGregor RR. Corynebacterium diphtheriae. In Mandell GL, Bennett JE, Dolin R, eds. Mandell, Douglas, and Bennett's Principles and Practices of Infectious Diseases, 7th ed. Philadelphia: Elsevier; 2009: 2687-2693.

6. Clark KEN. Review of Epidemiology of Diphtheria 2000-2016. Available at: https://www.who.int/ immunization/sage/meetings/2017/april/1_Final_rep ort_Clarke_april3.pdf. Accessed on 10 July 2019.

7. World Health Organization: Immunization, Vaccines and biological. Vaccine preventable diseases vaccine monitoring systems 2019 Global Summary References Time Series: diphteria. Available at: https://apps.who.int/immunization_ monitoring/globalsummary/timeseries/tsincidencedi phtheria.html. Accessed on 10 July 2019.

8. Sadoh AE, Oladokun RE. Re-emergence of diphtheria and pertussis: Implications for Nigeria. Vaccine. 2012;30:7221-8.

9. World Health Organization. The immunological basis for immunization series: module 2: diphtheriaupdate 2009. Geneva, Switzerland: World Health Organization; 2009.

10. Archary M, Cohen C, de Gouveia L, du Plessis M, McCarthy K, Mlisana K. Available at: http://www.nicd.ac.za/wp-content/uploads/2017/03/ NICD-guidelines_diphtheria_v3_28-May-2018.pdf. Accessed on 19 December 2019.

11. Paediatric Association of Nigeria Advisory Committee on Immunization. Paediatric Association of Nigeria recommended routine immunization schedule for Nigerian children. Niger J Paediatric. 2012;39:152-8.

Cite this article as: Abubakar MY, Lawal J, Dadi H, Grema US. Diphtheria: a re-emerging public health challenge. Int J Otorhinolaryngol Head Neck Surg 2020;6:191-3. 